\title{
Correction to: A group key-based lightweight Mutual Authentication and Key Agreement (MAKA) protocol for multi-server environment
}

\section{Prasanta Kumar Roy ${ }^{1}$ (D) Ansuman Bhattacharya ${ }^{1}$}

Published online: 22 October 2021

(C) Springer Science+Business Media, LLC, part of Springer Nature 2021

\section{Correction to: The Journal of Supercomputing https://doi.org/10.1007/s11227-021-04114-7}

In this article, the legend for Figs. 7 and 8 was wrong; the figures should have appeared as shown below.

Figure 7.

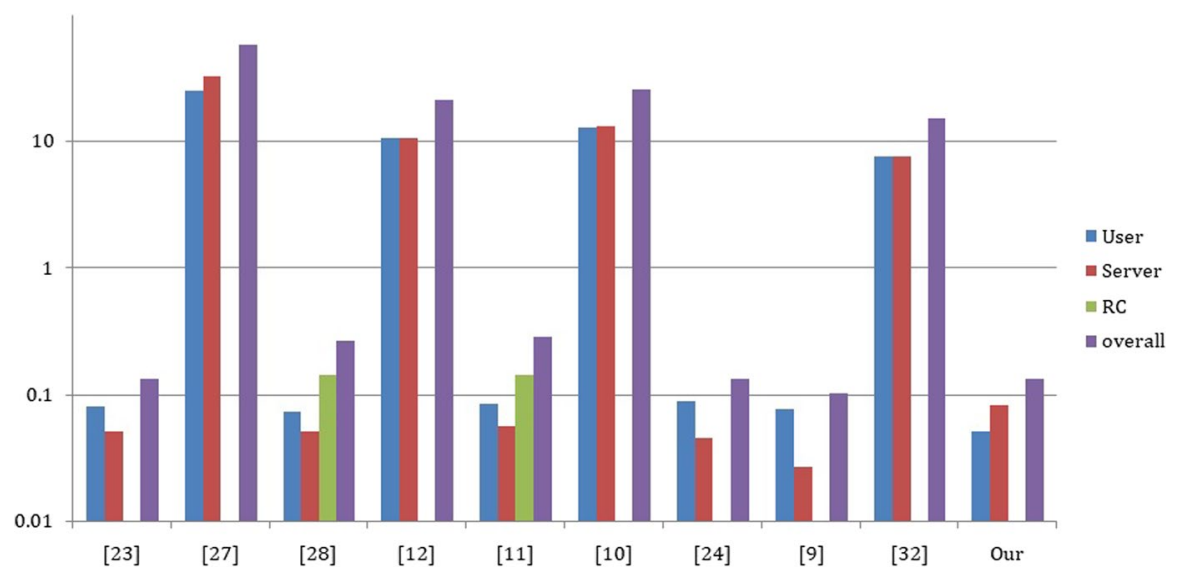

Fig. 7 Execution time (in logarithmic scale)

The original article can be found online at https://doi.org/10.1007/s11227-021-04114-7.

Prasanta Kumar Roy

prasanta201284@gmail.com

Ansuman Bhattacharya

ansuman@iitism.ac.in

1 Indian Institute of Technology (Indian School of Mines), Dhanbad 826004, India 


\section{Figure 8.}

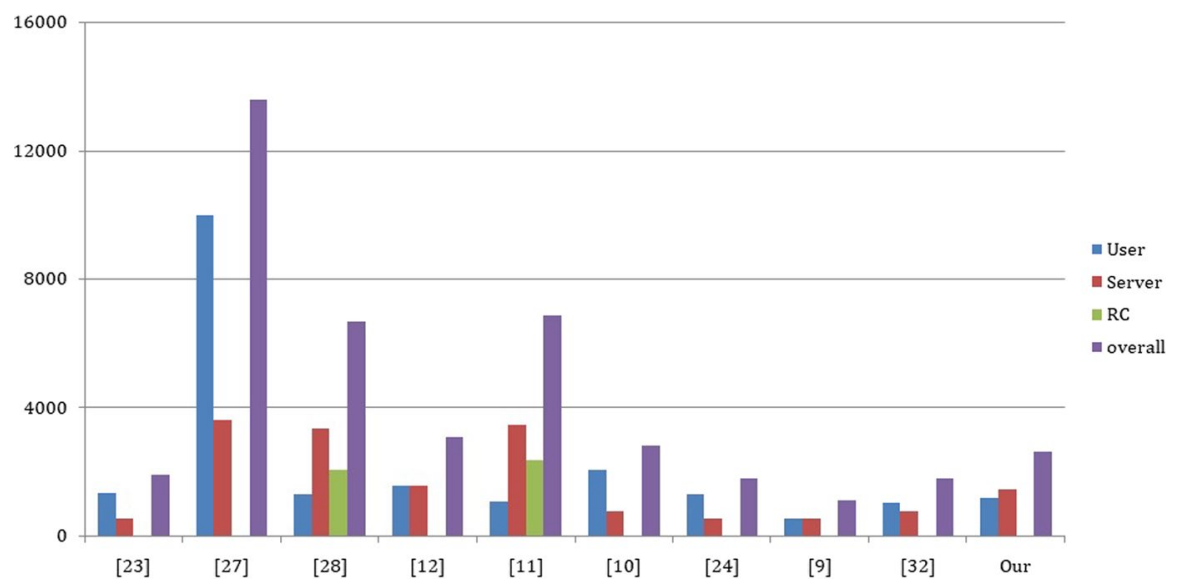

Fig. 8 Communication cost (in normal scale)

The original article has been corrected.

Publisher's Note Springer Nature remains neutral with regard to jurisdictional claims in published maps and institutional affiliations. 